\title{
The Irrigation Calculator - a decision support tool for dairy farmers
}

\author{
R.J. MARTIN ${ }^{1}$, R.F. ZYSKOWSKI ${ }^{1}$, S.M. THOMAS ${ }^{1}$, A.J. HORROCKS ${ }^{1}$ and D.R. STEVENS ${ }^{2}$ \\ ${ }^{I}$ Crop \& Food Research, PB 4704, Christchurch \\ ${ }^{2}$ AgResearch, Invermay Agricultural Centre, PB 50034, Mosgiel \\ martind@crop.cri.nz
}

\begin{abstract}
The Irrigation Calculator is a computer decision support tool that assists dairy farmers to decide when to irrigate, how much water to apply, and the consequences of wrong irrigation timings or amounts. The user interface has two data entry screens, one to enter background soils information, the other main screen for entering irrigator application times and amounts, grazings and run times. The Irrigation Calculator has been tested against actual pasture cut and plate data, and there was generally close agreement. Feedback from farmers who have been involved in testing and development has been positive, and their suggestions have been incorporated into a version that can be widely released to farmers.
\end{abstract}

Keywords: model, pasture growth, soil moisture, evapotranspiration

\section{Introduction}

Dairying in Canterbury depends on irrigation to produce consistently high pasture yields, and the area of irrigated dairy pasture has increased rapidly in recent years (Doak et al. 2004). The rapidly increasing demand for irrigation is approaching or exceeding the amount of water available for irrigation in some areas (Miller \& Veltman 2004). Many river-run irrigation schemes and areas with restricted ground water already face periodic irrigation restrictions, and this situation will worsen under current climate change predictions, which indicate warmer drier conditions for East Coast areas (Salinger 2007).

However, adoption of currently available efficient irrigation technology and best management practices could considerably increase pasture production per $\mathrm{mm}$ of water used (Martin et al. 2006), which would enable dairy farmers to adapt to increasing water restrictions, and progress towards the dairy industry target of a $40 \%$ reduction in water use over 10 years without compromising productivity (Dairy Insight 2006). More efficient irrigation practices could also reduce the high power consumption of many spray irrigators (Thomas et al. 2006), leading to significant cost savings on-farm and less power used nationally.

Many farmers would like to improve their irrigation systems but are constrained by lack of resources, time and incentives to obtain and apply the available information (Aqualink Research Limited 2006). However, many dairy farmers are positive about using tools to improve water use efficiency on-farm, and those interviewed as part of this project expressed a preference for simple computer programmes with minimal input of records so that answers can be obtained quickly.

Our objective was to design a prototype, easy to use computer decision support tool to meet this farmer preference. "The Irrigation Calculator" that has been developed assists dairy farmers to decide when to irrigate, how much water to apply, and the consequences of wrong irrigation timings or amounts. "Calculator" tools are already being used successfully for crops such as potatoes (Jamieson et al. 2004).

\section{Methods}

The calculator consists of four parts:

1. A pasture growth model

2. A soil water balance model

3. A paddock model which integrates part 1 and 2 over time

4. An irrigation model which incorporates water applications with part 3 .

\section{Pasture Growth Model}

The pasture growth model is based on the concept developed by Brereton et al. (1996) that pasture growth is directly proportional to the radiation received at the canopy surface:

Potential growth $=$ Radiation Use Efficiency * Light Interception

Based on data presented by Martin et al. (2006), potential growth rate is set as $0.55 \mathrm{~g}$ dry matter $/ \mathrm{m}^{2} / \mathrm{MJ}$ solar radiation. It is assumed that the pasture is predominantly perennial ryegrass grown under no management and nutrient limitations. There are three modifiers of the relationship with solar radiation:

a) Temperature

The relationship between potential pasture growth and temperature is based on McCall \& Bishop-Hurley (2003), using an optimum daily mean temperature of $21^{\circ} \mathrm{C}$, and a temperature modifier:

$1-\left(0.0025 *(\text { Actual daily mean temperature- } 21)^{2}\right)$

b) The amount of pasture present on a given day.

After grazing, there is reduced leaf area and incomplete light interception. To account for this, the amount of radiation intercepted is calculated from:

Light interception $=$ pasture mass $*$ specific leaf area, 
where specific leaf area is the ratio of leaf area to leaf dry mass, and is currently set at $25 \mathrm{~m}^{2} / \mathrm{kg}$, which approximates the findings of Arredondo \& Schnyder (2003) and Kemp et al. (2001). The actual pasture mass on a given day depends on the time since the last grazing date, and the residual left at that last grazing. The residual is currently set at $1500 \mathrm{~kg} \mathrm{DM} / \mathrm{ha}$, similar to the grazing residual target set by the Lincoln University Dairy Farm c) Soil Moisture Model

Soil water deficits are calculated using a water balance approach, i.e.

Water deficit today $=$ water deficit yesterday - irrigation - rainfall + evapotranspiration + drainage.

The water balance requires inputs of daily potential evapotranspiration (PET), rainfall and irrigation, and details of the soil available water holding capacity in the paddock. The potential soil moisture deficit is converted to an actual deficit using a simplified version of Scotter et al. (1979):

If rainfall $>$ PET, then AET $=$ PET

Otherwise AET $=\mathrm{K}$ (AWC- Deficit), where $\mathrm{K}=\mathrm{PET} /$ $\mathrm{AWC}$, where $\mathrm{AWC}$ is the available water holding capacity of the soil, i.e. the difference between field capacity and wilting point, and Deficit is the soil moisture deficit ( $\mathrm{mm}$ below field capacity (FC)).

The plant available water (PAW) is the amount of water in a given depth of soil above wilting point and equals AWC-Deficit. Currently we use $60 \mathrm{~cm}$ as our default soil depth, and we assume that yield will start to decline when PAW falls below $50 \%$ of AWC, so the objective is to keep the soil moisture between $50 \%$ of AWC and FC.

\section{The Irrigation Calculator Interface}

The user interface for the calculator has two data entry screens, a main irrigation screen (Fig. 1) and a secondary farm detail screen (Fig. 2). The farm detail screen contains farm and soil details. The farmer is able to select which weather station to use (this determines which weather data is used), paddock, soil type and pasture cover.

The main screen (Fig. 1) is divided into four parts (AD). In the top box (A) are the farm and soil data entered for that paddock, together with details of the irrigation management for the farmer to select or tick. The farmer can then chose to:

- Apply water at a fixed interval (which can be entered) or vary the interval

- Apply a fixed amount each time (which can be entered) or vary the amount

- Stop irrigating after a rainfall event; the current rule is that a rain event stops the irrigator for that day.

At the bottom of the main screen (B, Fig. 1) the start and stop dates for the irrigation schedule are displayed together with the date the schedule is calculated from (usually in the previous winter so that the soil is at field capacity). A dry or normal forecast can be selected for future scheduling. Irrigations and grazing information can be entered using the buttons at the bottom right of the screen. The "Calculate" button runs the model to give the new irrigation schedule and pasture yield information.

The chart in the centre of the screen (C, Fig. 1) shows the time course of rainfall, irrigations, and PAW in the soil to a depth of $60 \mathrm{~cm}$. The upper horizontal line is the amount of PAW at FC, and the lower horizontal line is the amount of PAW at $50 \%$ of AWC. If calculated PAW exceeds FC, then water will be lost to drainage or runoff. When PAW falls below the $50 \%$ line, the model calculates a loss of pasture growth due to estimated water stress. Therefore, to maximise pasture production and avoid wasting water, the farmer should schedule timing and amounts of irrigation to maintain PAW between the two horizontal lines.

The thick vertical line going to the top of the screen indicates the date to which the weather data have been updated, so to the left of that line, actual weather data are used, and to the right forecast data are used.

The box to the left of the screen (D, Fig.1) gives some summary outputs for the calculator:

- Time period being shown by the graph, set by the user.

- The potential dry matter production based on the management, weather and soil scenario entered. This feature enables farmers to predict what will happen under a given irrigation scenario, and also to evaluate their past irrigation management.

- The amount of rainfall and irrigation scheduled to be applied in the period selected.

- The forecast date when the next irrigation is due and the amount to be applied

\section{Results and Discussion}

We tested the model against three available data sets. These consisted of:

1. Pasture cuts taken approximately monthly using the cage technique (Lynch 1966) on a well watered paddock on the north block of the Lincoln University Dairy Farm during the 2006-07 season. There was a good match between the actual and calculated pasture yields (Fig. 3).

2. Yields calculated from the weekly pasture growth rate data for the whole Lincoln University Dairy Farm (South Island Dairying Development Centre 2008) over the 2006-07 and 2007-08 seasons. Figure 4 shows the time course of the published and calculated yields. There was a generally close match between the two data sets. The calculated yields tended to be lower than actual yields in the summer of 2006-07, but higher in the summer of 2007-08.

3. A short term, on-farm demonstration with actual 
Figure 1 Main screen of the Irrigation Calculator. $A=$ farm and irrigation management input box, $B=$ date and amounts input box, $C=$ results screen showing rainfall, irrigations and soil moisture, $D=$ production and irrigation summary output box.

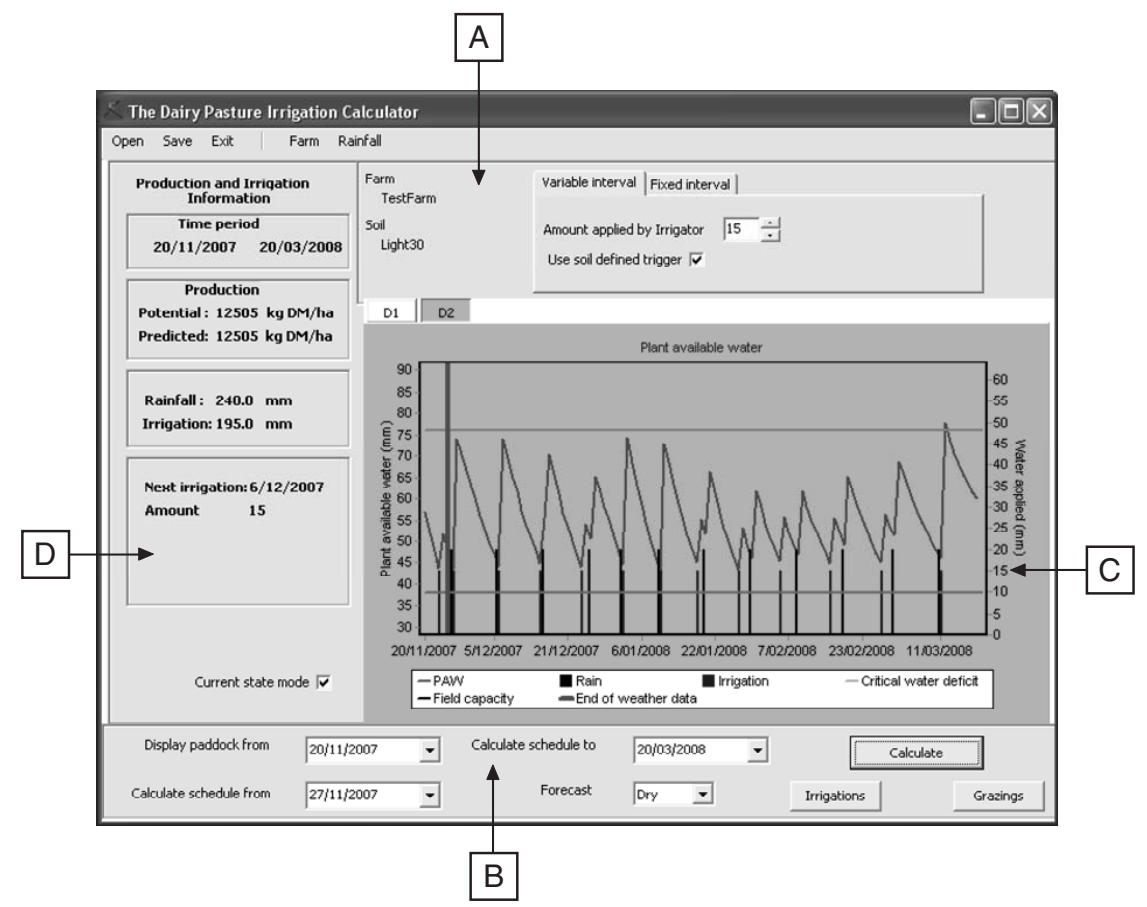

Figure 2 Second screen of the Irrigation Calculator where farmer can input soil, paddock and weather station data.

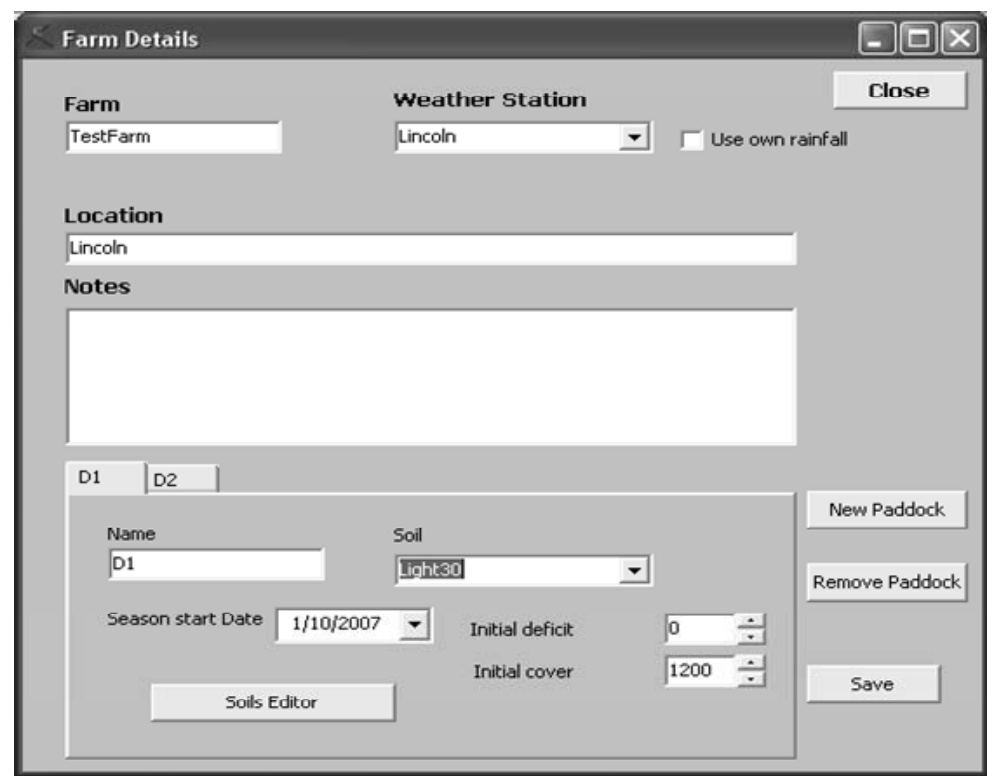


Figure 3 Relationship between measured pasture cut yield and calculated pasture yield $(\mathrm{kg} / \mathrm{ha})$ for paddock N11 on a Templeton Silt Loam soil at the Lincoln University Dairy Farm. Regression line is Measured Yield $=-180+0.957$ Predicted Yield $\left(P<0.001, R^{2}=0.77\right)$.

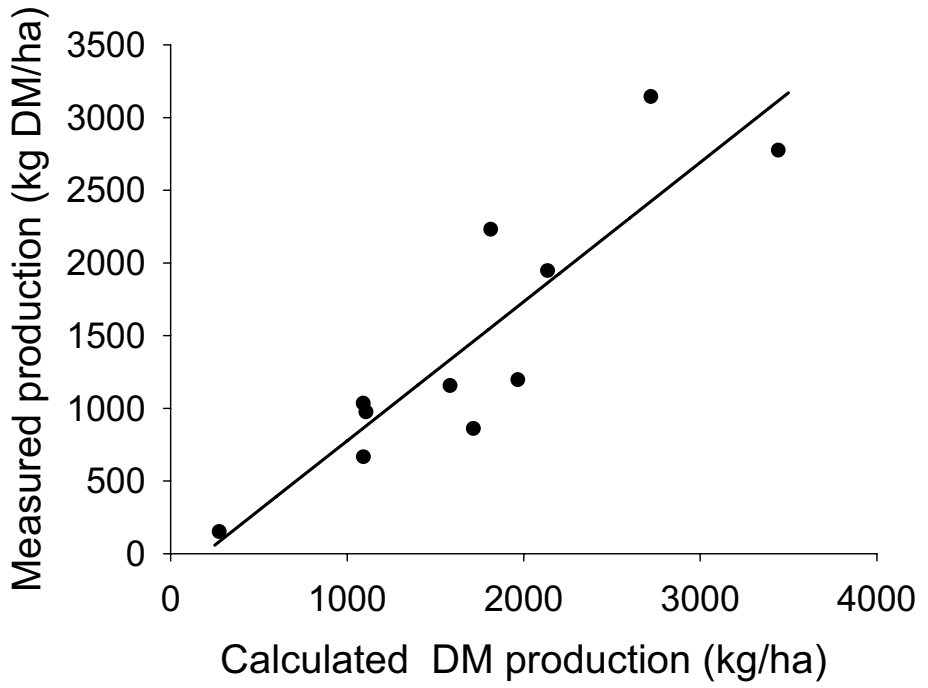

Figure 4 Measured pasture plate and calculated pasture yield $(\mathrm{kg} / \mathrm{ha})$ and dates for all paddocks at the Lincoln University Dairy Farm. Regression between the two yield data sets is Actual Yield $=-86.6+1.02$ Predicted Yield $\left(P<0.001, R^{2}=0.59\right)$.

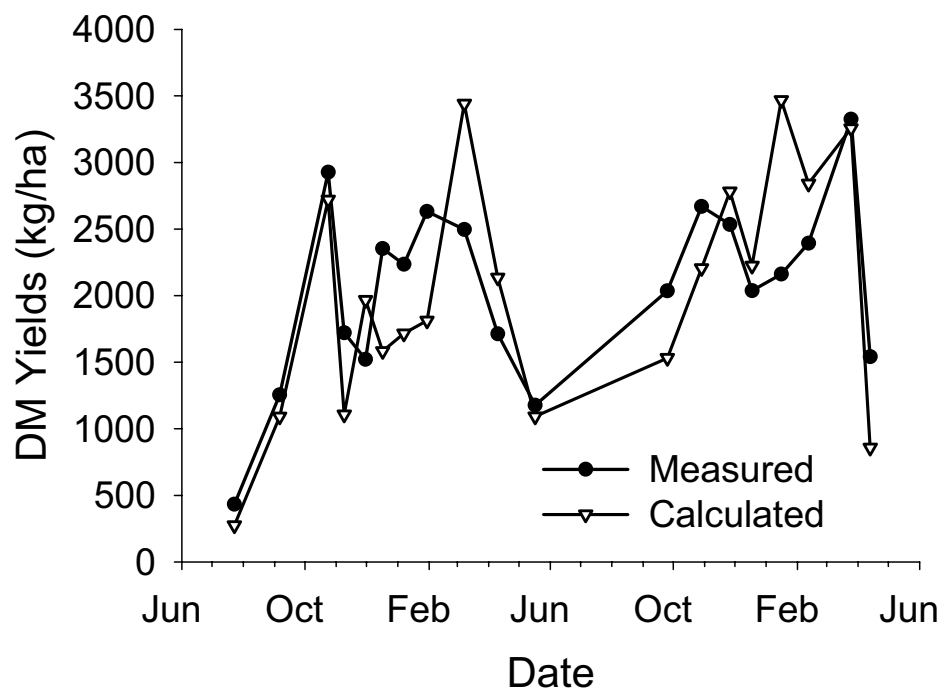

growth rates derived from pasture plate yields and Time Domain Reflectometry soil moisture measurements on four farms in April 2008 (Fig. 5). Actual and predicted growth rates matched well (under $4 \mathrm{~kg} / \mathrm{ha}$ /day difference). Similarly, at the end of the testing period there was a very close match between the measured and calculated soil moisture deficits in the top $60 \mathrm{~cm}$ ( $3 \mathrm{~mm}$ difference).

Some of the farmers supplied with the irrigation calculator actively tested it, and, based on their experience and comments, a number of improvements to the Irrigation Calculator interface and data management were identified.

Some practical issues that affected the utility of the calculator were identified when it was tested on-farm. A major limitation is the need for daily temperature and PET data from the nearest weather station. This currently needs to be provided as a separate file to be installed by 
Figure 5 Measured pasture plate and calculated pasture growth rates (kg DM/ha/day) and soil moisture deficits (mm) on four dairy farms in April 2008.

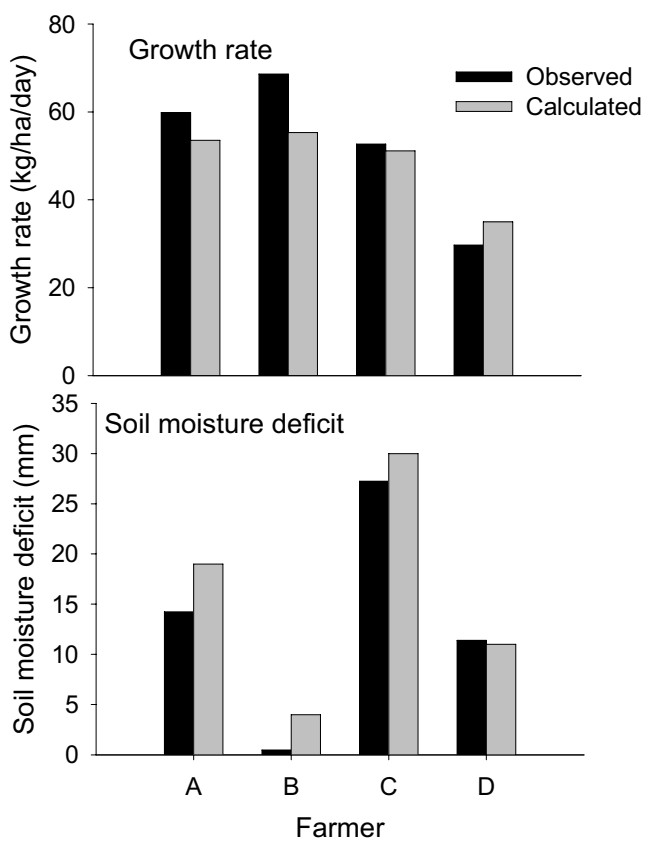

the user. This could be overcome in the future by a webdelivered calculator with automated processing and delivery of the weather data so that the farmer can get up to date information at any time. Otherwise the major requirement for the farmer is to keep the Calculator updated with accurate rainfall and irrigation amounts. In the farmer testing programme and from previous surveys (Thomas et al. 2006), it was found that some farmers do not accurately remember when they irrigate or know the amount they apply. This is now simple to rectify with better recording practices and on-farm checks (Page Bloomer Associates Ltd. 2006). As a check against missed or erroneous rainfall and irrigation entries, the Calculator can be calibrated occasionally against field measured soil moisture.

\section{Conclusions}

Our objective of designing a simple tool that can help farmers use their irrigation water more efficiently has been achieved. The limited validation to date indicated that the Calculator is a good predictor of dairy pasture yields. Some development work is needed to get weather data more readily available so that the Calculator can be used at any time.

\section{ACKNOWLEDGEMENTS}

Funding for this project was provided by Dairy Insight and DairyNZ. We acknowledge the assistance given by Westlea Clarke-Hill, Geoff Dunham, Tom Fraser, Cath
Goulter, Trevor Knight, Matt Riddle, Tracey Payne, Andrew Curtis and all of the farmers who tested the calculator for us.

\section{REFERENCES}

Aqualink Research Limited. 2006. Irrigation efficiency gaps - Review and Stock Take. Aqualink Report L05264/2. 39 pp. Http:/www.maf.govt.nz/sff/whatson/irrigation-efficiency-gaps.pdf

Arredondo, J.T.; Schnyder, H. 2003. Components of leaf elongation rate and their relationship to specific leaf area in grasses. New Phytologist 158: 305-314.

Brereton, A.J.; Danielov, S.A.; Scott, D. 1996. Agrometeorology of grass and grasslands for middle latitudes. World Meteorological Organization Technical Note $197.36 \mathrm{pp}$.

Dairy Insight. 2006. Dairy Industry Strategy for Sustainable Environmental Management. 21p. Http:// www.dairynz.co.nz/file/fileid/4174

Doak, M.; Parminter, I.; Horgan, G.; Monk, R.; Elliot, G. 2004: The economic value of irrigation in New Zealand. Technical Paper No. 04/01. Wellington, MAF Policy. 62 pp.

Jamieson, P.D.; Stone, P.J.; Zyskowski, R.F.; Sinton, S.M.; Martin, R.J. 2004. Implementation and testing of the Potato Calculator, a decision support system for nitrogen and irrigation management. pp 85-100. In: Decision Support Systems in Potato Production: Bringing Models to Practice. Eds. MacKerron, 
D.K.L.; Haverkort, A.J. Wageningen Academic Publishers, The Netherlands.

Kemp, P.D.; Tavakoli, H.; Hodgson, J. 2001. Physiological and morphological responses of tall fescue and perennial ryegrass to leaf defoliation. Proceedings 10th Australian Agronomy Conference, Hobart. Http://www.regional.org.au/au/asa/2001/2/d/ kemp.htm

Lynch, P.B. 1966. Conduct of Field Experiments. N.Z. Department of Agriculture Bulletin No. 399. 154 pp. Martin, R.J.; Thomas, S.M.; Stevens, D.R.; Zyskowski, R.F.; Moot, D.J.; Fraser, T.J. 2006. Improving water use efficiency on irrigated dairy farms in Canterbury. Proceedings New Zealand Grassland Association 68: 155-160.

McCall, D.G.; Bishop-Hurley, G.J. 2003. A pasture growth model for use in a whole-farm dairy production model. Agricultural Systems 76: 11831205.

Miller, M.G.; Veltman, A. 2004. Proposed Canterbury natural resources plan for river and groundwater allocation policies and the implications for irrigation dependent farming in Canterbury. Proceedings of the New Zealand Grassland Association 66: 11-23.

Page Bloomer Associates Ltd. 2008. IRRIG8-Lite irrigation performance checks. Http:// www.pagebloomer.co.nz/IRRIG8Lite.html.

Salinger, J. 2007. Climate change and variability in Canterbury. p 6. In: Agscience, November 2007.

Scotter, D.R.; Clothier, B.E.; Turner, M.A. 1979. The soil water balance in a fragiaqualf and its effect on pasture growth in central New Zealand. Australian Journal of Soil Research 17: 455-465.

South Island Dairying Development Centre. 2008. Lincoln University Dairy Farm Weekly Data Archive. Http://www.siddc.org.nz/weekly_data_archive.html Thomas, S.M; Bloomer, D, Martin, R.J.; Horrocks, A. 2006. Spray irrigation on dairy pastures - efficient or not? Proceedings of the New Zealand Grasslands Association 68: 177-181. 